\title{
Formation of meta-subject components of ICT competence
}

\author{
Margarita Ivanovna Shutikova ${ }^{1 *}$ and Valentina Aleksandrovna Matveeva ${ }^{2 \dagger}$ \\ ${ }^{1}$ Academy of Social Management, Department of General Education Disciplines, Moscow, Russia \\ ${ }^{2}$ Sakhalin State University, Department of Math, Yuzhno-Sakhalinsk, Russia
}

\begin{abstract}
The changes in education dictated by the 4th industrial revolution and the specifics of training future teachers in primary education associated with the multidimensionality of pedagogical activities give grounds for refining the structural and content model of ICT competence of future teachers in primary education. In the contemporary information society, establishing a holistic view of the unity of information processes is a prerequisite for educational process organization. The insufficient level of ICT competence in future teachers in primary education and the need to achieve meta-disciplinary results in education serve as a basis for the clarification and specification of the model of this concept. The authors propose an expansion of the invariant component composition of ICT competence with meta-subject components (the variable core of the competence): semiotic, technological, and integrative. Refining the structural and content model and identifying the methods and techniques that contribute to the formation of ICT competence in future teachers in primary education and allow reaching meta-subject results. One of the main instruments contributing to the formation of ICT competence is mathematical modeling based on the universal sign-symbol system and most suitable for designing computer models. The methodology based on the method of cross-curricular tasks allows achieving meta-subject results in the construction of the educational process of training future teachers in the field of primary education. Research demonstrates that enriching the educational process of future teachers in primary education with schematic, graphic, and geometric tools and the implementation of the method of cross-cutting tasks that serves as a leading means of teaching mathematics contribute to the emergence of a stable positive dynamic in the formation of information culture, particularly the meta-subject components of ICT competence of future teachers in the field of primary education.
\end{abstract}

Keywords: meta-subject components of ICT competence: semiotic, technological, integrative.

\footnotetext{
* Corresponding author: raisins 7@mail.ru

† Corresponding author: matveeva89.ru@mail.ru
} 


\section{Introduction}

The world of "signs" and "texts" gains crucial importance in the contemporary information society. The role of knowledge is largely transforming due to the volume and speed of dissemination of data filling the surrounding reality. The ability to work with data solely determines whether we obtain an information product and true knowledge or remain cut away from the world of "texts".

In the modern world of automated and "intelligent" technology, the emphasis of the educational process is shifting dramatically which is dictated by the fundamentally new reality of the 4th industrial revolution. Teaching new pre-established algorithms and models is no longer relevant. More valuable today is the acquisition of universal skills of working with data: analyzing, synthesizing, classifying, generalizing, etc. Thus, a special, fundamental role in the acquisition of universal basic knowledge and skills is played by "humanitarian informatics" [1: 1] that examines information processes beyond "facts and technology" [1: 1] and attributes the defining role to information and its properties. Many researchers (S.A. Beshenkov, E.V. Mindzaeva, E.A. Rakitina, I.I. Trubina, M.I. Shutikova) emphasize the special role of information modeling (particularly mathematical modeling) in the process of expanding the subject of computer science towards a meta-subject.

\section{Methods}

Competence in the sphere of ICT is one of the major requirements for the training of modern specialists. A teacher as a subject of pedagogical activity who contributes to the development of students' socially adaptive personalities has to teach them the basics of interaction in the information society. Fulfilling the requirements of the Federal State Educational Standard [2] is a vital prerequisite for training future teachers in the sphere of primary education, one of the criteria for their training is "systematic and critical thinking" manifesting in "the ability to search for, critically analyze, and synthesize information" which points towards competence in the field of ICT. The need for ICT competencies is also stated in the professional standard "Teacher", the main document regulating the performance of a teacher's job functions.

Many researchers (S.A. Beshenkov, M.I. Shutikova, E.V. Mindzaeva) emphasize that the study of any phenomena and processes of reality is associated with information modeling. Different social systems are subject to the same principles of information interaction: systematicity, symmetry, uncertainty, additionality, incompleteness of the formal system, and "nonlinearity" [1:2], which allows us to consider the meta-dimensionality of information processes and their integrative functions. We argue mathematical models as most suitable for the construction of computer models as they result from a rigorous formal presentation with the use of the universal sign-symbolic system (the universality of mathematical language is undeniable) which is not the case for other models, for instance, the literary information models. Thus, mathematical modeling presents a necessary instrument for the formation of the meta-subject component of ICT competence [1, 3-5]

Analysis of the content of the concept of ICT competence of primary school teachers [6] demonstrate that the authors do not consider the content of this concept in terms of the polyaspect nature of training primary school teachers and the general pedagogical nature of the components of ICT competence (cognitive, motivational and value, operational and activity, professional-methodological, communicative, and reflexive and evaluative components) needs further specification through meta-subject components which will allow forming the variable core of ICT competence.

- The semiotic component - mastery of universal sign systems capable of providing a differentiated linguistic representation of information flow units. 
- The technological component - the ability to use semantic units competently when creating educational information models, making inferences, and establishing the informational and conceptual isomorphism and homomorphism.

- The integrative component - the ability to effectively conduct information interaction in the conditions of the pedagogical process. The performance of the integrative function in mastering different subject areas to "connect" concepts and form a unified image of the world, a comprehensive view of information processes, and a holistic worldview.

Let us examine the process of formation of meta-subject components on an example.

Table 1. Formation of meta-subject components ICT competence of future teachers in primary education.

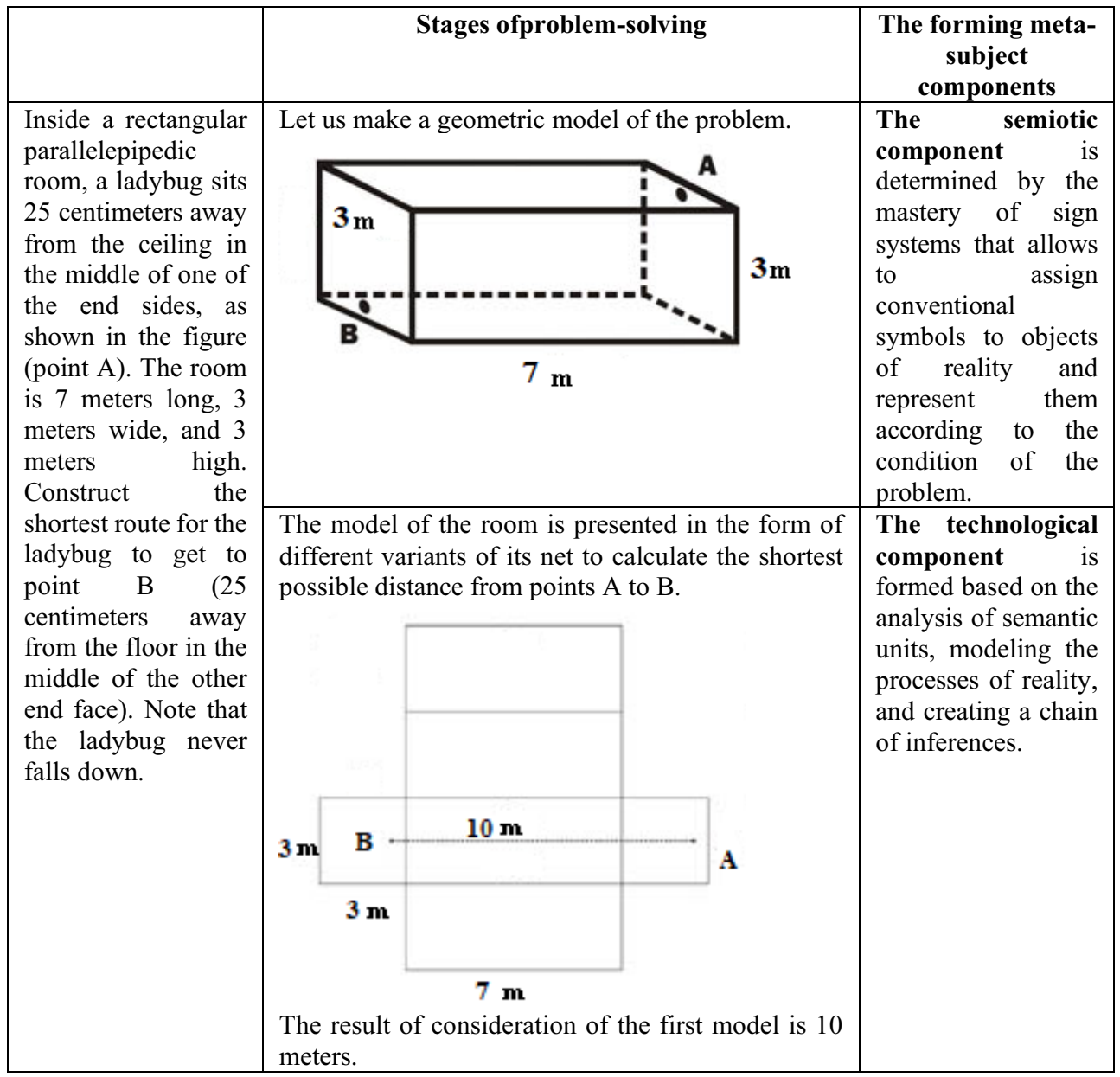




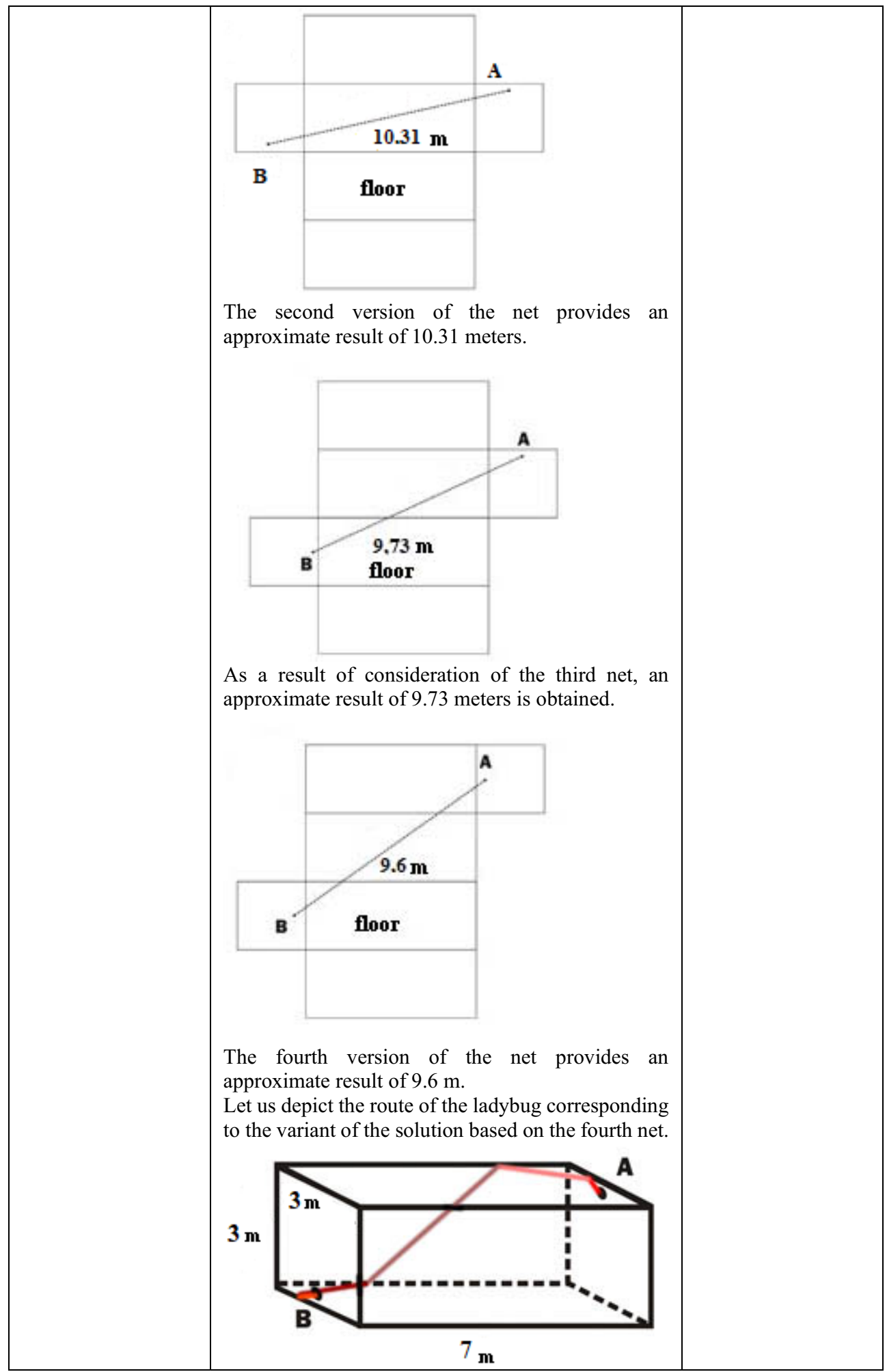




\begin{tabular}{|l|l|l|}
\hline & $\begin{array}{l}\text { Spatial thinking is a necessary basis for creating } \\
\text { spatial images and structures. This type of mental } \\
\text { activity allows analyzing spatial structures, } \\
\text { transforming their properties, and achieving the } \\
\text { optimal conditions for decision-making. }\end{array}$ & $\begin{array}{l}\text { integrative } \\
\text { component } \\
\text { determined } \\
\text { establishing } \\
\text { isomorphism of real } \\
\text { the } \\
\text { phenomena with the } \\
\text { concepts of formal } \\
\text { science } \\
\text { formation a } \\
\text { unified image of the } \\
\text { world). }\end{array}$ \\
\hline
\end{tabular}

The example shown in Table 1 demonstrates that mathematical models contribute to the formation of meta-subject components since solving them requires operating with sign systems (constructing a model), analyzing the resulting sign units (constructing a chain of inferences), and transforming the properties of formal objects to optimize the conditions of the surrounding reality. One can notice that the result of the problem varies depending on the location of points A and B $(50 \mathrm{~cm}, 75 \mathrm{~cm}$, etc.) relative to the ceiling and floor which allows researching this issue. The use of software tools, for example, GeoGebra, will allow optimizing both the visualization process and research activity when solving this problem. The implementation of the cross-cutting tasks method in constructing the educational process allows considering the mathematical model from different points of view and reveals the applied value of mathematical knowledge. New information for students has to come from a "living" model showing the genesis and the logic of disclosure of mathematical concepts. This approach helps to achieve meta-subject results in education [7].

\section{Results and discussion}

V.A. Testov notes that spatial thinking and particularly "geometric imagination is necessary for many areas of human activity - from the field of mathematical art to mathematical modeling and programming" [8: 13]. In contemporary visually saturated information environment, the role of figurative and especially spatial thinking increases significantly. Back in the 1970s, Russian psychologist V.P. Zinchenko stated that "in the near future, images will be an extremely effective means of human-machine communication" [9: 44]. Research by Russian psychologists (V.P. Zinchenko, V.M. Munipov, V.M. Gordon) shows that "the language of images is no less of a means of modeling a problem situation than speech" [10:13], therefore, the reduction in the volume of geometrical material in school mathematics significantly impoverishes the means of stimulating imagination leading to difficulties in the development of figurative and particularly spatial thinking, which, in turn, contradicts the challenges of the modern information society [11-15].

\section{Conclusion}

Thus, filling the educational process of future primary school teachers with schematic, graphic, and geometric instruments appears to be the leading pedagogical condition for the effectiveness of the formation of information culture, particularly ICT competence, in primary education specialists. The meta-subject components of ICT competence of future teachers in primary education are a logical consequence of the expansion of its invariant core (the general pedagogical component composition: cognitive, motivational and value, operation and activity, professional-methodological, communicative, and reflexive and evaluative components) of the variable component (semiotic, technological, and integrative 
components). The use of mathematical methods and models together with software applications form the optimal pedagogical environment for the formation of meta-subject components of ICT competence in the training of teachers in the sphere of primary education.

\section{References}

1. S.A. Beshenkov, E.A. Rakitina, M.I.Shutikova, Informatika i Obrazovaniye, 2, 3-8, (2008)

2. Federal State Educational Standard of Higher Education 3++ in the direction of training 44.03.05 Pedagogical Education (with two training profiles) (Bachelor's level): [Order No. 125 of February 22, 2018] (2018). Accessed on: October 10, 2020. [Online]. Available: http://fgosvo.ru/fgosvo/151/150/24/94

3. S.A. Beshenkov, G.I. Alekseeva, M.I. Shutikova, Mir Obrazovaniia, 2, 48-54 (2008)

4. S.A. Beshenkov, M.I. Shutikova, E.V. Mindzaeva, Konferentsium ASOU: a collection of scientific works and proceedings of scientific and practical conferences, 4, 39-46 (2017)

5. M.I. Shutikova, Scientific and Methodological Electronic Journal "Koncept", 4, 10561060 (2013)

6. S.A. Beshenkov, V.A. Matveeva, Bulletin of Peoples' Friendship University of Russia. Series: Informatization of Education, 17(3), 190-200 (2020). https://doi.org/10.22363/2312-8631-2020-17-3-190-200

7. V.A. Matveeva, Izvestiia of the Institute of Pedagogy and Psychology of Education: Electronic Journal (2020). Accessed on: October 12, 2020. [Online]. Available: http://izvestia-ippo.ru

8. V.A. Testov, Education and Science, 1, 4-20 (2016). https://doi.org/10.17853/19945639-2016-1-4-20

9. V.P. Zinchenko, Voprosy Filosofii, 11, 42-47 (1973)

10. V.P. Zinchenko, V.M. Munipov, V. M. Gordon, Voprosy Filosofii, 2, 3-14 (1973)

11. L. Darling-Hammond, J. Bransford (Eds.), Theories of learning and their roles in teaching, in Preparing teachers for a changing world, 40-87 (Jossey-Bass, San Francisco, 2005)

12. P. Grossman, C.P. Dean, S.S. Kavanagh, Z. Herrmann, Phi Delta Kappan, 100(7), 4348 (2019)

13. K.Turvey, N.Pachler, Computers \& Education, 146, 103736 (2020). https://doi.org/10.1016/j.compedu.2019.103736

14. J. Loughran, Teachers and Teaching, 25(5), 523-535 (2019)

15. M. Tang, C.H. Werner, Thinking Skills and Creativity, 24, 268-278 (2017). https://doi.org/10.1016/j.tsc.2017.04.001. 